\title{
Is the Quality of the Patient-Provider Relationship Associated with Better Adherence and Health Outcomes for Patients with HIV?
}

\author{
Mary Catherine Beach, MD, MPH, 1,2,3,4 Jeanne Keruly, MS, CNRP, ${ }^{1}$ \\ Richard D. Moore, MD, MHS \\ 'Division of General Internal Medicine, Department of Medicine, Johns Hopkins University School of Medicine, Baltimore, MD, USA; \\ ${ }^{2}$ Phoebe R. Berman Bioethics Institute, Johns Hopkins University, Baltimore, MD, USA; ${ }^{3}$ Department of Health Policy and Management, \\ Johns Hopkins Bloomberg School of Public Health, Baltimore, MD, USA; ${ }^{4}$ Welch Center for Prevention, Epidemiology, and Clinical \\ Research, Johns Hopkins University, Baltimore, MD, USA; 5 Department of Epidemiology, Johns Hopkins Bloomberg School of Public Health, \\ Baltimore, MD, USA.
}

PURPOSE: Patient-centeredness, originally defined as understanding each patient as a unique person, is widely considered the standard for high-quality interpersonal care. The purpose of our study was to examine the association between patient perception of being "known as a person" and receipt of highly active antiretroviral therapy (HAART), adherence to HAART, and health outcomes among patients with HIV.

STUDY DESIGN: Cross-sectional analysis.

SUBJECTS: One thousand seven hundred and forty-three patients with HIV.

MEASUREMENTS: Patient reports that their HIV provider "knows me as a person" and 3 outcomes: receipt of HAART, adherence to HAART, and undetectable serum HIV RNA.

RESULTS: Patients who reported that their provider knows them "as a person" were more likely to receive HAART (60\% vs $47 \%, P<.001$ ), be adherent to HAART ( $76 \%$ vs $67 \%, P=.007$ ), and have undetectable serum HIV RNA ( $49 \%$ vs $39 \%, P<.001$ ). Patients who reported their provider knows them "as a person" were also older (mean 38.0 vs 36.6 years, $P<.001$ ), reported higher quality-of-life (mean LASA score 71.1 vs $64.8, P<.001$ ), had been followed in clinic longer (mean 64.4 vs 61.7 months, $P=.008$ ), missed fewer appointments (mean proportion missed appointments 0.124 vs $0.144, P<.001$ ), reported more positive beliefs about HAART therapy (39\% vs $28 \%$ strongly believed HIV medications could help them live longer, $P<.008$ ), reported less social stress (50\% vs $62 \%$ did not eat regular meals, $P<.001$ ) and were less likely to use illicit drugs or alcohol $(22 \%$ vs $33 \%$ used drugs, $P<.001 ; 42 \%$ vs $53 \%$ used alcohol, $P<.001)$. Controlling for patient age, sex, race/ ethnicity, quality-of-life, length of time in clinic, missed appointments, health beliefs, social stress, and illicit drug and alcohol use, patients who reported their provider knows them "as a person" had higher odds of receiving HAART (odds ratio [OR] 1.41, 95\% confidence interval [CI] 1.19 to 1.65 ), adhering to HAART (OR $1.33,95 \%$ CI 1.02 to 1.72 ), and having undetectable serum HIV RNA (1.20, 95\% CI 1.02 to 1.41$)$.

CONCLUSIONS: We found that a single item measuring the essence of patient-centeredness - the patients' perception of being "known as a person"-is significantly and independently associated with receiving HAART, adhering to HAART, and having undetectable serum HIV RNA. These results support the hypothesis that the quality of patient-physician relationship is directly related to the health of patients.

KEY WORDS: patient-physician relations; patient-centeredness; HIV, HAART; adherence; quality of care.

The authors have no conflicts of interest to report.

Address correspondence and requests for reprints to Dr. Beach: Johns Hopkins University School of Medicine, 2024 East Monument Street, Suite 2-500, Baltimore, MD 21287, 410-614-1134 (e-mail: mcbeach@jhmi.edu).
DOI: $10.1111 /$ j.1525-1497.2006.00399.x J GEN INTERN MED 2006; 21:661-665.

$\mathrm{P}$ atient-centeredness, originally defined as "understanding each patient as a unique human being,"1 is now widely considered the standard for high-quality interpersonal care. ${ }^{2}$ Patients who report that their physicians exhibit patient-centered communication behaviors are significantly more satisfied with their care ${ }^{3-5}$ and report greater improvements in general medical condition. ${ }^{4}$ Furthermore, studies which have directly observed patient-provider communication have been found that patient-centered communication is associated with patient satisfaction and health outcomes among patients with chronic diseases such as diabetes and hypertension. ${ }^{6-8}$

Several qualitative studies and editorials have suggested that the effective patient-physician relationships and communication may improve adherence to therapy among patients with HIV, ${ }^{9-13}$ but there are limited data. Adherence to highly active antiretroviral therapy (HAART) is particularly important for patients with HIV, as strict adherence to drug regimens is important to avoid drug resistance, disease progression, and death. ${ }^{14}$ Two recent studies have reported a positive association between the quality of patient-provider relationships and self-reported adherence to HAART ${ }^{15,16}$ which provides strong preliminary evidence that interpersonal aspects of health care may directly correlate with the health of patients with HIV.

Because Safran et al. ${ }^{17}$ have found that patient perception of their provider having "whole person knowledge" is one of the strongest predictors of adherence to therapy in the primary care setting, we hypothesized that a single item which captures the essence of patient-centeredness-the patient perception of being known "as a person" — would be significantly associated with adherence to HAART among patients with HIV. Furthermore, we hypothesized that patient perception of being known "as a person" would also be related to the appropriate receipt of HAART and to subsequent health outcomes.

Manuscript received July 21, 2005

Initial editorial decision October 4, 2005

Final acceptance December 15, 2005 


\section{METHODS}

\section{Design, Subjects, and Setting}

We conducted a cross-sectional analysis of 4,694 interviews with 1,743 patients (mean $=2.69$ interviews per patient) to evaluate the association between patient reports that their HIV provider "knows me as a person" and 3 outcomes: receipt of HAART, adherence to HAART, and absence of detectable serum HIV RNA. This study took place within the context of the Johns Hopkins HIV Cohort Study, ${ }^{18}$ which routinely interviews patients every 6 months using an audio computer-assisted survey instrument (ACASI). Patients were interviewed while awaiting or after completing an appointment with their primary care provider at an urban clinic specializing in HIV care. Data for this analysis were collected from 2000 to 2003.

\section{Measures}

We developed a single item for this study to measure the quality of the patient-provider relationship The item was developed with input from a Community Advisory Board of HIV-infected persons, and it is derivative of the original definition and core feature of patient-centeredness: understanding each patient as a person rather than a disease or set of symptoms. ${ }^{1}$ The item asked patients to respond "yes," "no" or "don't know" to the statement, "My HIV provider really knows me as a person." This item was felt to have face validity by the Community Advisory Board as well as by investigators with expertise in patient-centeredness.

For our primary analyses, the association of the above measure was determined for the following 3 outcome measures. (1) Receipt of HAART measured by patient self-report and confirmed by chart review. Patients were considered to be taking HAART if they were on any regimen that met national guidelines ${ }^{19}$ for antiretroviral therapy relevant to that date. (2) For the patients receiving HAART, adherence to HAART measured using a validated survey ${ }^{20}$ in which patients are asked to report how many doses they have missed using a 24hour, 3-day, and 2-week recall. In this study, we considered patients adherent to HAART if they had not missed any doses in the past 3 days. (3) Serum HIV-1 RNA measured using the Roche Amplicor assay within 4 weeks of the patient interview. Patients with less than 400 copies/ $\mu \mathrm{L}$ were considered to have undetectable serum HIV RNA.

Other covariates in the analysis, measured using the ACASI, included patient age, sex, race/ethnicity, HIV transmission risk group, any cigarette, alcohol, and illicit drug use in the previous 6 months, health beliefs (measured by 4 questions that assessed knowledge related to the treatment of HIV), social stress (measured by 2 questions dealing with whether or not stress affects the subject's ability to take medications and whether or not the patient ate regular meals), and overall quality-of-life (measured using the Linear Analog Scale Assessment $(\text { LASA })^{21}$ on which a higher score indicates a better quality-oflife). In addition, we measured time as enrollment into the HIV clinic (measured using administrative data) and CD4 lymphocyte count (measured by flow cytometry).

\section{Analysis}

Our analysis was cross-sectional. Our independent variable was patient perception of being known "as a person," which we dichotomized to compare respondents who answered "yes" with those who answered "no" or "don't know." Our 3 outcome variables were dichotomous as described above. We used logistic regression to assess the associations between patient reports of being known "as a person" and each outcome. All estimates (adjusted and unadjusted) use the generalized esti-

Table 1. Study Subjects

\begin{tabular}{|c|c|c|c|c|c|}
\hline \multicolumn{3}{|l|}{ Demographics } & \multicolumn{3}{|l|}{ Social stress } \\
\hline Mean age & 37.7 & & Eats regular meals & 2246 & $(47.9 \%)$ \\
\hline Sex & & & Stress affects ability to take medicines & 1142 & $(24.6 \%)$ \\
\hline Male & 2871 & $(61.2 \%)$ & & & \\
\hline Female & 1823 & $(38.8 \%)$ & Health care process & & \\
\hline Race/ethnicity & & & Receiving HAART & 2707 & $(57.7 \%)$ \\
\hline White & 610 & $(13.0 \%)$ & Length of time in clinic (mo) & 64.0 & \\
\hline African American & 4034 & $(85.9 \%)$ & & & \\
\hline Other & 50 & $(1.1 \%)$ & Adherence & & \\
\hline HIV risk factor & & & Adherent to HAART* & 2027 & $(74.9 \%)$ \\
\hline Male-to-male sex & 1082 & $(23.1 \%)$ & Mean proportion missed appointments & 0.127 & \\
\hline Heterosexual sex & 1561 & $(33.3 \%)$ & & & \\
\hline \multirow[t]{2}{*}{ IVDU } & 2329 & $(49.6 \%)$ & Health Status & & \\
\hline & & & Mean LASA QOL & 70.08 & \\
\hline Substance use & & & HIV stage & & \\
\hline Alcohol past $6 \mathrm{mo}$ & 2043 & $(43.5 \%)$ & AIDS & 2136 & $(45.9 \%)$ \\
\hline Cigarettes past $6 \mathrm{mo}$ & 3054 & $(66.5 \%)$ & Symptomatic & 634 & $(13.6 \%)$ \\
\hline Any drugs past $6 \mathrm{mo}$ & 1132 & $(24.1 \%)$ & Asymptomatic & 1885 & $(40.5 \%)$ \\
\hline \multirow{2}{*}{ Drug use ever } & 2961 & $(68.5 \%)$ & CD4 at time of interview & 360 & \\
\hline & & & RNA at time of interview & 53735 & \\
\hline Health beliefs & & & RNA less than 500 & 2150 & $(47.3 \%)$ \\
\hline Will live longer if take HIV medicines & 1736 & $(37.0 \%)$ & & & \\
\hline Will get sick if don't take medicines & 1483 & $(31.6 \%)$ & & & \\
\hline Medicines will prevent hospital admission & 936 & $(20.0 \%)$ & & & \\
\hline Medicines will prevent symptoms & 1387 & $(29.6 \%)$ & & & \\
\hline
\end{tabular}

*Defined as not having missed any does for $3 d$ preceding interview, analysis limited to respondents on HAART.

HAART, highly active antiretroviral therapy; BOL, quality of life; LASA, linear analog scale assessment. 
mating equation to adjust the variance estimates for multiple interviews of the same patients. Data were analyzed using Stata Version 7.0.

\section{RESULTS}

\section{Study Sample}

Characteristics of the study sample are presented in Table 1. The population was young (mean age 37.7 years), mostly male (61.2\%), mostly African American (85.9\%), and the most prominent HIV transmission risk factor was injecting drug use (49.6\%). There was a high prevalence of substance abuse; $43.5 \%$ reported using any alcohol in the past 6 months, $66.5 \%$ used cigarettes in the past 6 months, and $24.1 \%$ used illicit drugs in the past 6 months. There was a fairly high level of social stress, with only $47.9 \%$ reporting that they ate regular meals. Subjects had been followed in the clinic an average of 64.0 months at the time of the survey.

\section{Factors Associated with Patient Reports that Provider Knows Them "As a Person"}

The associations between patients' perception that they are known "as a person" and other patient characteristics are presented in Table 2. In unadjusted analyses, patients who reported that their provider knows them "as a person" were more likely to receive HAART ( $60 \%$ vs $47 \%, P<.001$ ), be adherent to HAART (76\% vs $67 \%, P=.007$ ), and have undetectable serum HIV-1 RNA ( $49 \%$ vs $39 \%, P<.001$ ). Figure 1 depicts the associations between the 3 categories of being known "as a person" and each of these 3 outcome variables. There is a monotonic increasing association between each of these outcome variables and being known "as a person".

Patients who reported their provider knows them "as a person" were older (mean 38.0 vs 36.6 years, $P<.001$ ), reported higher quality-of-life (mean LASA score 71.1 vs 64.8 , $P<.001$ ), had been followed in clinic longer (mean 64.4 vs 61.7 months, $P=$.008), missed fewer appointments (mean proportion missed appointments as HIV clinic enrollment 0.124 vs $0.144, P<.001$ ), reported more positive beliefs about HAART therapy ( $39 \%$ vs $28 \%$ strongly believed HIV medications could help them live longer, $P=.008$ ), reported less social stress $(50 \%$ vs $62 \%$ did not eat regular meals, $P<.001)$ and were less likely to use illicit drugs or alcohol ( $22 \%$ vs $33 \%$ used drugs, $P<.001 ; 42 \%$ vs $53 \%$ used alcohol, $P<.001$ ).

Unadjusted and adjusted analyses are presented in Table 3. After controlling for patient age, sex, race/ethnicity, qualityof-life, length of time in clinic, missed appointments, health beliefs, social stress, and illicit drug and alcohol use, patients who reported their provider knows them "as a person" had higher odds of receiving HAART (odds ratio [OR] 1.41, 95\% confidence interval [CI] 1.19 to 1.65 ), adhering to HAART (OR 1.33, 95\% CI 1.02 to 1.72) and having undetectable serum HIV RNA (1.20, 95\% CI 1.02 to 1.41). After additional adjustment for whether or not the patient was receiving HAART, the association between the patients' perception that the provider knew them "as a person" and having undetectable serum HIV RNA was no longer significant.
Table 2. Associations Between Patient Characteristics and Patient Reports That Their HIV Provider Knows Them 'As a Person'

\begin{tabular}{|c|c|c|c|}
\hline & \multicolumn{3}{|c|}{ Provider Knows as a Person } \\
\hline & $\begin{array}{c}\text { Yes } \\
N=3,910\end{array}$ & $\begin{array}{c}\text { No/Don't } \\
\text { Know } \\
N=784\end{array}$ & $\begin{array}{c}P \text { - } \\
\text { Value }\end{array}$ \\
\hline \multicolumn{4}{|l|}{ Demographics } \\
\hline Mean age & 38.0 & 36.6 & $<.001$ \\
\hline \multicolumn{4}{|l|}{ Sex } \\
\hline$\%$ Male & 61.0 & 62.1 & .741 \\
\hline$\%$ Female & 39.0 & 37.9 & \\
\hline \multicolumn{4}{|l|}{ Race/ethnicity } \\
\hline$\%$ White & 12.7 & 14.7 & .234 \\
\hline$\%$ African American & 86.1 & 85.0 & \\
\hline \multicolumn{4}{|l|}{ HIV Risk Factor* } \\
\hline$\%$ male to male sex & 23.0 & 23.1 & .510 \\
\hline$\%$ heterosexual sex & 33.2 & 33.8 & .855 \\
\hline$\%$ IVDU & 49.7 & 49.2 & .781 \\
\hline \multicolumn{4}{|l|}{ Substance Use } \\
\hline$\%$ Alcohol past $6 \mathrm{mo}$ & 41.6 & 53.1 & $<.001$ \\
\hline$\%$ Cigarettes past $6 \mathrm{mo}$ & 66.3 & 67.2 & .324 \\
\hline$\%$ Any drugs past $6 \mathrm{mo}$ & 22.3 & 33.4 & $<.001$ \\
\hline$\%$ Drug use ever & 67.6 & 73.3 & .027 \\
\hline \multicolumn{4}{|l|}{ Health Beliefs } \\
\hline $\begin{array}{l}\% \text { Believe will live longer if } \\
\text { take HIV medicines }\end{array}$ & 38.8 & 28.2 & .008 \\
\hline $\begin{array}{l}\% \text { Believe will get sick if don't take } \\
\text { medicines }\end{array}$ & 33.3 & 23.2 & $<.001$ \\
\hline $\begin{array}{l}\text { \% Believe medicines will prevent } \\
\text { hospital admission }\end{array}$ & 21.7 & 11.1 & $<.001$ \\
\hline $\begin{array}{l}\% \text { Believe medicines will prevent } \\
\text { symptoms }\end{array}$ & 31.6 & 19.5 & $<.001$ \\
\hline \multicolumn{4}{|l|}{ Social stress } \\
\hline$\%$ Eats regular meals & 49.8 & 38.3 & $<.001$ \\
\hline $\begin{array}{l}\% \text { Stress affects ability to take } \\
\text { medicines }\end{array}$ & 22.5 & 35.2 & $<.001$ \\
\hline \multicolumn{4}{|l|}{ Health care process } \\
\hline \% Receiving HAART & 59.8 & 47.2 & $<.001$ \\
\hline Length of time in clinic (months) & 64.4 & 61.7 & .008 \\
\hline \multicolumn{4}{|l|}{ Adherence } \\
\hline$\%$ Adherent to HAART ${ }^{\dagger}$ & 76.1 & 67.3 & .007 \\
\hline $\begin{array}{l}\text { Mean proportion missed } \\
\text { appointments }\end{array}$ & 0.124 & 0.144 & $<.001$ \\
\hline \multicolumn{4}{|l|}{ Health Status } \\
\hline Mean LASA QOL score & 71.1 & 64.8 & $<.001$ \\
\hline \multicolumn{4}{|l|}{ HIV stage } \\
\hline$\%$ AIDS & 46.1 & 44.6 & .316 \\
\hline$\%$ symptomatic & 14.1 & 11.4 & .316 \\
\hline$\%$ asymptomatic & 39.8 & 44.0 & .316 \\
\hline Mean CD4 at time of interview & 362 & 350 & .555 \\
\hline$\%$ RNA less than 500 & 49.0 & 39.1 & $<.001$ \\
\hline
\end{tabular}

${ }^{*}$ Responses not mutually exclusive.

${ }^{\dagger}$ Defined as not having missed any does for 3 days preceding interview, analysis limited to respondents on HAART.

HAART, highly active antiretroviral therapy; $B O L$, quality-of-life; LASA, linear analog scale assessment.

\section{DISCUSSION}

Our study demonstrates that the essence of patient-centeredness-the patient's perception of being known "as a person"is significantly and independently associated with receiving HAART, adhering to HAART, and having undetectable serum HIV RNA. These associations persist even after controlling for multiple potential confounders, and confirms the findings of 2 previous studies ${ }^{16,22}$ that the quality of patient-provider relationship is significantly associated with adherence to HAART. 


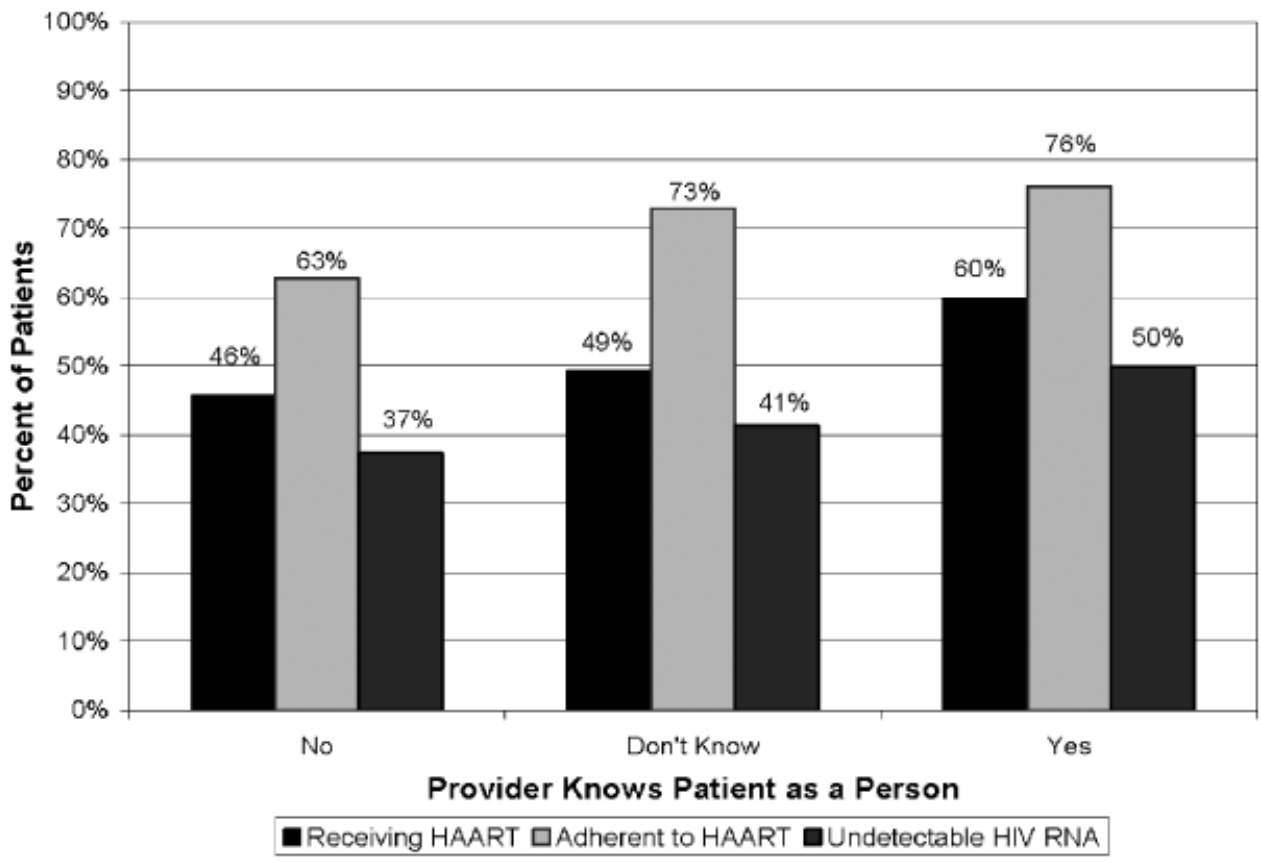

FIGURE 1. Associations between patient reports that provider knows them "As a Person" and patient outcomes.

This study adds to our current knowledge in several important ways. First, in addition to the association between patient-provider relationship quality and adherence to HAART (among those for whom HAART was prescribed), we found an association between patient-provider relationship quality and the appropriate receipt of HAART in the first place. This association remained significant even after controlling for the length of time the patient was followed in the clinic (suggesting that it is not just that the physician has not found the time to prescribe HAART), the patient's health beliefs (suggesting that it is not just that the patient doesn't accept that HAART is useful), and other patient features that the clinician might use to decide whether the patient was a candidate for HAART (such as CD4 count or active substance abuse).

In addition, we found that the quality of the patient-provider relationship is associated with having an undetectable serum HIV-1 RNA which is a strong clinical predictor of future health for patients with HIV. The association between patients' reports of being known "as a person" and suppression of HIV-1 RNA was no longer significant after adjusting for HAART receipt, indicating that it is the receipt of HAART that is the primary mediator for the association with a suppressed HIV-1 RNA. Nevertheless, the fact that patients who are known "as a person" are also more likely to adhere to HAART when prescribed suggests a second mechanism through which higher quality patient-provider relationships may impact patient health.

One important issue that our study raises is the feasibility of improving patient experience of care in general, and the ability to improve upon the health professional's ability to make a patient feel known "as a person" in particular. Are interpersonal aspects of care modifiable? Two recent systematic reviews evaluating the effectiveness of interventions designed to promote patient-centered medicine and cultural competence have confirmed that such interventions can improve provider behavior. ${ }^{23,24}$ Thus, we have reason to be encouraged that educational interventions targeted at health professionals can improve patient experience. However, it would be useful for further research to explore how best to improve interpersonal aspects of care for patients with HIV and their providers.

It is worth noting that, although our independent variable-being known "as a person"-captures the essence of patient-centeredness, it is also a fairly nonspecific measure. Further research is needed to determine exactly what patients were thinking when reporting that their provider knows or does not know them "as a person." Our own qualitative work

Table 3. Associations Between Patient Reports That Their Provider Knows Them 'As a Person'* and Patient Outcomes

\begin{tabular}{|c|c|c|c|c|c|c|}
\hline & \multicolumn{3}{|c|}{ Univariate } & \multicolumn{3}{|c|}{ Multivariate } \\
\hline Receipt of HAART & 1.66 & 1.42 to 1.94 & $<.001$ & 1.41 & 1.19 to 1.65 & $<.001$ \\
\hline$<500$ copies / $\mu$ L HIV RNA & 1.49 & 1.27 to 1.75 & $<.001$ & 1.20 & 1.02 to 1.41 & .029 \\
\hline
\end{tabular}

*All analyses compare patient who answered 'yes' to patients who answered 'no' or 'don't know' that their provider knows them as a person.

Controlling for patient age, sex, race/ethnicity, drug use, alcohol use, social stress, health beliefs, length of time followed in clinic, proportion of missed appointments, and quality-of-life.

OR, odds ratio; CI, confidence interval; HAART, highly active antiretroviral therapy. 
has begun to explore this concept through in-depth interviews with a sample of 28 primary care patients. Preliminary analysis suggests that there are modifiable factors-such as remembering a patient's name, establishing good rapport, listening carefully, asking questions to learn about their lives and later remembering and following up on this information with patients-that might be useful to providers interested in improving their relationships with patients. In addition to uncovering specific physician behaviors that allow patients to feel known as a person, further research might also investigate the most effective means to increase the patients' perception of being known as a person. For example, it is unknown whether it is more effective to teach physicians a set of specific behaviors, or simply to give physicians a goal-that patients ought to feel known as a person-and then allow each physician to use his/her own communication repertoire to meet this goal.

Several limitations are also worth noting. First, as with any observational study, there is the potential for unmeasured confounding. For example, it may be that patient ratings of their relationship with their doctor and self-reported adherence are both part of some global trait such as a positive outlook. However, the fact that our findings persist even after controlling for many other variables, such as self-reported quality-of-life, which may also be thought of as part of a positive outlook, is an indication that we are indeed measuring 2 different concepts.

Second, as with any cross-sectional analysis, causality cannot be determined. Although we believe that it is more likely that effective patient-physician relationships are the cause of patient adherence, the reverse is possible. It is conceivable that physicians of patients who are adherent feel and act more positively towards those patients. Further longitudinal research is needed to determine the direction of causality. Finally, we conducted our study at just one clinic, and so there is uncertain generalizability of our results to other settings.

Adherence to HAART is one of the most challenging issues facing patients with HIV and their providers. Our study suggests that the essence of patient-centeredness-the patient's perception that they are known "as a person"-may be one important aspect of patient adherence and may directly influence the health of patients with HIV. Efforts to improve health care quality, adherence, and health of persons with HIV should focus on improving the patient-provider relationship. Further research is needed to determine how this is best accomplished.

Dr. Beach is a Robert Wood Johnson Generalist Physician Faculty Scholar and a recipient of a K-08 grant from the Agency for Healthcare Research and Quality. Other grant support: RO1 DA 1 1602, K24 DA 11602, R21 AA105032.

\section{REFERENCES}

1. Balint E. The possibilities of patient-centred medicine. J Roy Coll Gen Pract. 1969; 17:269-76.

2. Committee on Quality Health Care in America. Crossing the Quality Chasm: A New Health System for the 21st Century. Washington, DC: National Academy Press; 2001.

3. Kaplan SH, Gandek B, Greenfield S, Rogers W, Ware JE Jr. Patient and visit characteristics related to physicians' participatory decision-making style. Results from the medical outcomes study. Med Care. 1995;33: $1176-87$.

4. Brody DS, Miller SM, Lerman CE, Smith DG, Caputo GC. Patient perception of involvement in medical care: relationship to illness attitudes and outcomes. J Gen Intern Med. 1989;4:506-11.

5. Lerman CE, Brody DS, Caputo GC, Smith DG, Lazaro CG, Wolfson HG. Patients' perceived involvement in care scale: relationship to attitudes about illness and medical care. J Gen Intern Med. 1990;5:29-33.

6. Stewart M, Brown JB, Donner A, et al. The impact of patient-centered care on outcomes. J Fam Pract. 2000;49:796-804.

7. Stewart MA. Effective physician-patient communication and health outcomes: a review. Can Med Assoc J. 1995;152:1423-33.

8. Kaplan SH, Greenfield S, Ware JE Jr. Assessing the effects of physicianpatient interactions on the outcomes of chronic disease. Med Care. 1989;27(3 Suppl):S1 10-S127.

9. Schilder AJ, Kennedy C, Goldstone IL, Ogden RD, Hogg RS, O'Shaughnessy MV. "Being dealt with as a whole person." Care seeking and adherence: the benefits of culturally competent care. Soc Sci Med. 2001;52:1643-59.

10. Murri R, Antinori A, Ammassari A, et al. Physician estimates of adherence and the patient-physician relationship as a setting to improve adherence to antiretroviral therapy. J Acquir Immune Defic Syndr. 2002;31(Suppl 3):158-S162.

11. Wu AW, Ammassari A, Antinori A. Adherence to antiretroviral therap: where are we, and where do we go from here? J Acquir Immune Defic Syndr. 2002;31(Suppl 3):95-S97.

12. Roberts KJ. Physician-patient relationships, patient satisfaction, and antiretroviral medication Adherence among HIV-infected adults attending a public health clinic. AIDS Patient Care STDS. 2002;16: 43-50.

13. Davis-Michaud M, Yurk R, Lansky D, Asch S, Wu AW. Quality care for people with HIV/AIDS: patients' perspectives. HIV Clin Trials. 2004;5:406-15.

14. Paterson DL, Swindells S, Mohr J, et al. Adherence to protease inhibitor therapy and outcomes in patients with HIV infection. Ann Intern Med. 2000; 133:21-30.

15. Bakken S, Holzemer WL, Brown MA, et al. Relationships between perception of engagement with health care provider and demographic characteristics, health status, and adherence to therapeutic regimen in persons with HIV/AIDS. AIDS Patient Care STDS. 2000;14:189-97.

16. Schneider J, Kaplan SH, Greenfield S, Li W, Wilson IB. Better physician-patient relationships are associated with higher reported adherence to antiretroviral therapy in patients with HIV infection. J Gen Intern Med. 2004; 19:1096-1103.

17. Safran DG, Taira DA, Rogers WH, Kosinski M, Ware JE, Tarlov AR. Linking primary care performance to outcomes of care. J Fam Pract. 1998;47:213-20.

18. Moore RD. Understanding the clinical and economic outcomes of HIV therapy: the Johns Hopkins HIV clinical practice cohort. J Acquir Immune Defic Syndr Hum Retrovirol. 1998;17(Suppl 1):38-S41.

19. U.S. Department of Health and Human Services (DHHS). Guidelines for the Use of Antiretroviral Agents in HIV-1-Infected Adults and Adolescents. [cited 2005 Apr. 13]; Available from URL:http://aidsinfo.nih.gov

20. Chesney MA, Ickovics JR, Chambers DB, et al. Self-reported adherence to antiretroviral medications among participants in HIV clinical trials: the AACTG adherence instruments. Patient care committee \& adherence working group of the outcomes committee of the adult AIDS clinical trials group (AACTG). AIDS Care. 2000; 12:255-66.

21. Gough IR, Furnival CM, Schilder L, Grove W. Assessment of the quality of life of patients with advanced cancer. Eur J Cancer Clin Oncol. 1983; 19:1161-5.

22. Bakken S, Holzemer WL, Brown MA, et al. Relationships between perception of engagement with health care provider and demographic characteristics, health status, and adherence to therapeutic regimen in persons with HIV/AIDS. AIDS Patient Care STDS. 2000;14: 189-97.

23. Lewin S, Skea ZC, Entwistle V, Zwarenstein M, Dick J. Interventions for providers to promote a patient-centred approach in clinical consultations (Cochrane Review). The Cochrane Library. Issue 2 ed. 2002.

24. Beach MC, Price EG, Gary TL, et al. Cultural competence: a systematic review of health care provider educational interventions. Med Care. 2005;43:356-73. 